\title{
UM PALIMPSESTO IMPOSSÍVEL
}

\author{
Dilma Castelo Branco Diniz \\ UFMG
}

\begin{abstract}
RESUMO
Este estudo trata da questão do exílio em Le figuier enchanté, de Marco Micone, um escritor italiano imigrante no Quebec. O autor revela a problemática da adaptação em outro país, através de uma visão ao mesmo tempo pessoal e coletiva, mostrando que a cultura do imigrante é sempre híbrida, um palimpsesto impossível.
\end{abstract}

\section{PALAVRAS - CHAVE}

Exílio. Cultura do imigrante. Literatura quebequense.

J'ai reçu en héritage les mots que mon père trouvait beaux.[...] Ces mots sont ceux de mon enfance. Tant qu'ils évoqueront un monde que les mots d'ici ne pourront saisir, je resterai un immigrant lacéré par une double nostalgie. ${ }^{1}$

Marco Micone

$\mathrm{U}_{\mathrm{m}}$ dos fenômenos mais importantes da literatura quebequense do final do século XX, sobretudo a partir dos anos 1980, é a publicação de obras de autores imigrados que escolheram o Quebec e o francês como língua de comunicação artística.

Daniel Chartier, na introdução do seu Dictionnaire des écrivains émigrés au Québec:1800-1999, nos revela que os escritores nascidos no estrangeiro já constituem a quinta parte dos escritores do Quebec, ou seja, o dobro da proporção que se encontra na população em geral. Basta esse fato para mostrar o papel relevante desse movimento, que pode ser considerado uma verdadeira imigração literária. ${ }^{2}$

Essa literatura é chamada de "migrante" ou "literatura de imigração" - qualificação insatisfatória, pois traduz sempre uma situação à parte: uma literatura "diferentemente" quebequense. Assim concebida, além de problematizar a questão do espaço literário, essa literatura mostra-se ambígua: literatura imigrante de língua francesa ou literatura quebequense? Nesse caso, a ação de nomear constitui um importante fator de naturalização, como já observou Simon Harel, que também indaga "se não se trataria de uma literatura

\footnotetext{
${ }^{1}$ MICONE. Le figuier enchanté, p. 99. "Recebi por herança as palavras que meu pai achava bonitas. [...] Essas palavras são aquelas da minha infância. Enquanto elas evocarem um mundo que as palavras daqui não poderão captar, permanecerei um imigrante dilacerado por uma dupla nostalgia". A tradução é de minha autoria, assim como as outras que se seguem.
}

${ }^{2}$ CHARTIER. Dictionnaire des écrivains émigrés au Québec, p. 7. 
'étnica' escrita nas margens da cultura quebequense 'oficial'". ${ }^{3}$ O fato é que ela existe e costuma trabalhar de modo inovador as temáticas da identidade, do espaço, da memória, da alteridade e do exílio, embora se saiba que esses temas se encontram quase sempre imbricados. Neste estudo, tentarei mostrar de que modo o exílio é tratado por Marco Micone, em Le figuier enchanté. ${ }^{4}$ Como o texto revela a problemática do exílio numa visão pessoal, sem contudo deixar de lado as questões coletivas, convém lembrar aqui alguns dados biográficos do autor.

Marco Micone nasceu na Itália em 1945, em Montelongo, e emigrou com sua família para Montreal, no Canadá, em 1958. Depois de estudar numa escola inglesa e defender uma dissertação de mestrado em Letras sobre o teatro de Marcel Dubé, na Universidade McGill, ele ensina a língua e a cultura italianas no colégio Vanier. Preocupado com os problemas de marginalização da comunidade ítalo-quebequense, ele escreve uma trilogia para o teatro: Gens du silence (1982), Addolorata (1984) e Déjà l' agonie (1988). Quatro anos mais tarde, em 1992, publica a narrativa Le figuier enchanté, que obteve o prêmio das "Arcades de Bologne", no ano seguinte.

Esses dados autobiográficos, sempre ligados à questão da escrita, aparecem, claramente, neste trecho de Le figuier enchanté:

Au mois de septembre, j'entrepris des études en littérature française. Lorsque je découvris que Ionesco était un immigré roumain, je pensai qu'il n'était pas impossible qu'un jour, moi aussi, je puisse écrire. Il ne me restait qu'à approfondir ma connaissance du phénomène migratoire. Ce que je fis en enseignant la culture immigrée à des jeunes dont la plupart était d'origine italienne. ${ }^{6}$ (p. 85)

Nessa citação, percebe-se que a escrita concerne o escritor não sob a forma de acontecimentos relatados, mas de uma prática enunciativa, de uma vontade de levar à obra um desejo ou uma exigência de decifração. Trata-se de uma escrita engajada e esclarecedora, que encontrou uma certa reação em sua própria comunidade: "Je n'avais prévu ni l'insécurité résultant du babélisme dans lequel je baignais, ni l'hostilité du quarteron de plumitifs de ma communauté”. (

Ao tratar das relações entre a escrita e a vida, num ensaio sobre a biografia que tem por base a obra de Maurice Blanchot, Thierry Durand afirma:

Du sujet de l'énoncé (la vie de l'écrivain) on passe au sujet de l'énonciation (la vie de l'écrivain écrivant). L'expérience est ce glissement: de l'autobiographie classique (considérée ici comme un leurre), on passe à une nouvelle forme de biographie (la vie de

\footnotetext{
${ }^{3}$ HAREL. Le voleur de parcours, p. 280.

${ }^{4}$ MICONE. Le figuier enchanté. Montréal: Boréal, 1998. Todas as citações seguidas do número da(s) página(s) correspondente(s) são tiradas dessa edição.

${ }^{5}$ WEINMANN; CHAMBERLAND (Dir.). Littérature québécoise, p. 284.

6 "No mês de setembro, comecei a estudar a literatura francesa. Quando descobri que Ionesco era um imigrante romeno, pensei que não seria impossível que um dia eu também pudesse escrever. Só me restava aprofundar o conhecimento do fenômeno migratório. Fiz isso ensinando a cultura imigrada a jovens dos quais a maioria era de origem italiana".

7 "Não havia previsto nem a insegurança resultante do babelismo no qual estava mergulhado, nem a hostilidade do punhado de maus escritores da minha comunidade".
} 
l'écriture). L' écrivain ne cesse de disparaître mais survit, tant bien que mal, pour porter l'exigence de l'écriture, pratique expiatoire infinie. ${ }^{8}$

Realmente, Le figuier enchanté, de Marco Micone, apresenta uma inovação no modo de se escrever uma biografia (ou autobiografia). O termo "experiência" é por si só revelador. Diz-se de uma experiência que ela é enriquecedora, que acrescenta ao nosso saber, contribui para uma maior maturidade. Nesse sentido, a escrita é para o seu autor o signo de seu poder criativo.

O livro traça o itinerário de Nino, um garoto que nasceu e passou a infância numa aldeia do sul da Itália, uma região rural muito pobre, e, na adolescência, emigrou para o Canadá com sua mãe, seguindo os passos do pai, Carlo. São fatos que se encontram, portanto, muito próximos dos dados biográficos do autor, uma proximidade que é reforçada pela narração em primeira pessoa. Outro traço que reafirma essa ligação é a data das cartas escritas pelo pai do menino: a primeira, de julho de 1951, e sobretudo a última, de dezembro de 1957, pouco antes da viagem de Nino e sua mãe à América. Como já vimos, Marco Micone e sua mãe emigram para o Canadá em 1958, seguindo os passos de Carlo, seu pai.

O texto se compõe de quatorze capítulos, que contêm pequenas narrativas de diversos acontecimentos e lembranças da infância, algumas cartas e diversas impressões do menino, sendo que o último capítulo se apresenta como um texto teatral: um diálogo entre duas mulheres que esperam o início da sessão, numa sala de conferência. Talvez seja por isso que o autor denomina seu texto de um "recueil hybride" (p. 13), ou seja, uma coletânea híbrida.

Esse diálogo, fortemente marcado pela ironia, se passa entre Anne, uma quebequense francófona, e Manuela, uma imigrante que, apesar de ser fluente em quatro línguas - inglês, francês, italiano e espanhol -, por não ter seu diploma de professora ainda reconhecido, é obrigada a trabalhar como costureira numa fábrica. Depois do relato das diversas dificuldades enfrentadas pelos imigrantes no Quebec, a sessão começa com a palavra do conferencista:

Comme tant d'autres, j'ai été obligé d'émigrer. Rares sont ceux qui quitteraient leur lieu d'origine si la situation politique et économique ne les y forçait. Car, à part une minorité privilégiée, les autres n'en retirent...9 (p. 117)

O exílio se apresenta portanto como uma fatalidade. Com exceção de uma minoria privilegiada, as pessoas são obrigadas a deixar o seu país, quase sempre por razões econômicas e políticas. Essa obrigação de partir de sua terra natal deixa, no exilado, marcas que o acompanharão por toda a vida.

\footnotetext{
${ }^{8}$ DURAND. L'écriture ou la vie, p. 123. "Do sujeito do enunciado (a vida do escritor) passa-se ao sujeito da enunciação (a vida do escritor escrevendo). A experiência é esse deslizar: da autobiografia clássica (considerada aqui como um engodo), passa-se a uma nova forma de biografia (a vida da escrita). $\mathrm{O}$ escritor não cessa de desaparecer, mas sobrevive, nem bem nem mal, para suportar a exigência da escrita, prática expiatória infinita”.

9 "Como tantos outros, fui obrigado a emigrar. Raros são aqueles que deixariam seu lugar de origem se a situação política e econômica não os forçasse a isso. Porque, à exceção de uma minoria privilegiada, os outros não se retiram...”.
} 
No primeiro capítulo, com o título retórico de "Exorde", ${ }^{10}$ o narrador conta que sua infância transcorreu numa pequena vila encravada nas colinas da Itália meridional, marcada pela guerra e pela emigração. $O$ menino não aceitava entretanto que, ao lado do monumento aos heróis mortos no campo de honra, não houvesse outro, dez vezes maior, para lembrar os desaparecidos da emigração. Conta que, em cem anos, perto de vinte e cinco milhões de italianos deixaram seu país, alguns indo, no final do século XIX, substituir os escravos recém-libertados da América do Sul, e outros se espalhando pela América do Norte. Relata ainda que atitudes racistas sempre existiram ao longo da história da imigração no Canadá. Basta lembrar as taxas que os chineses tiveram que pagar, no início do século XX, para entrar no país e também as internações e espoliações que sofreram os italianos e os japoneses durante a Segunda Guerra mundial. Confessa então que, quando essas descobertas se juntam à certeza de que a emigração não existiria se ela não fosse de grande proveito, em primeiro lugar, ao país receptivo, a indignação surge e o imigrante se torna às vezes escritor. Essa frase deixa transparecer uma das raízes de sua escrita - a indignação - "une collère belle et ample, à la fois personnelle et collective", na expressão de Lori Saint-Martin. ${ }^{11}$

Utilizando o ponto de vista infantil, marcado pela inocência, o autor toca fundo na emoção do leitor, como, por exemplo, no dia da partida do pai: "Je ne comprenais pas pourquoi il émigrait. Je croyais que nous étions bien au village, et être mieux ailleurs n'avait aucun sens pour moi"12 (p. 35); ou algum tempo depois, dividido entre o amor do pai e do avô: "Avec le temps, je m'étais tellement attaché à grand-père que le chagrin que j'éprouvais à l'idée de le quitter me faisait oublier la crainte de ne plus revoir mon père"13 (p. 41).

A discriminação contra o imigrante e a vida dura que leva em Montreal surgem nas cartas do pai para a esposa Anna. Por causa dos baixos salários, Carlo mora em casa de uma prima, que é viúva, junto com outros três imigrantes. Um deles, que trabalha à noite, dorme em sua cama durante a tarde. Ironicamente, a prima diz que ele tem sorte, já que sua cama está sempre quente. Esse homem estava voltando para a Calábria e, quando Carlo perguntou o porquê dessa atitude, exibiu uma placa arrancada da vizinhança com os seguintes dizeres: "Pas de chiens, pas d'Italiens". ${ }^{14}$ E por incrível que pareça, a discriminação vem até dos próprios italianos. Carlo revela que está trabalhando para um italiano que trata os operários como cachorros. No fim de semana, obriga-os a construir um chalé sem nenhum pagamento. Conta também que se encontrou com italianos do norte que tratavam mal os conterrâneos do sul, criticando seu falar entrecortado. Revela ainda que vive com os pés e as mãos no cimento dez horas por dia e que está rodeado de homens que não vêem suas famílias há muitos anos. Ao filho confessa que, logo que

\footnotetext{
10 "Exórdio".

${ }^{11}$ Trecho transcrito na quarta capa de Le figuier enchanté. "Uma cólera bela e ampla, ao mesmo tempo pessoal e coletiva".

12 "Eu não compreendia por que ele emigrava. Acreditava que estávamos bem no vilarejo, e estar melhor em qualquer outra parte não fazia nenhum sentido para mim".

13 "Com o tempo, eu estava tão agarrado a meu avô que a tristeza que sentia com a idéia de deixá-lo me fazia esquecer o medo de não mais rever meu pai”.

14 "Nem cachorros, nem italianos".
} 
puder, vai trabalhar numa fábrica, pois no canteiro de obras acontece ao menos um acidente por semana. Em outra carta, dizia que ia voltar assim que pudesse e que a imagem paradisíaca da América era uma fabricação dos agentes da emigração e de politiqueiros.

$\mathrm{Na}$ última carta que escreve ao filho, dois meses antes de o menino partir da Itália, em capítulo que tem o título significativo de "La répétition", ou seja, o ensaio (de uma obra musical ou teatral), Carlo ensina ao menino: "Pour bien te préparer à émigrer, prends note de tout ce que tu n'aimes pas au village. Tu en auras besoin lorsque le désir de rentrer sera plus fort que tout"15 (p. 58).

O livro também denuncia a cultura italiana machista. As mulheres cujos maridos emigraram eram vigiadas por toda a comunidade da aldeia; e uma pessoa de sua família ficava encarregada de, algumas vezes por ano, escrever ao marido um relatório sobre a conduta da esposa. Convém dizer que os maridos nem sempre lhes enviavam dinheiro, e elas passavam por dificuldades. Mas a crítica mais acerba a esse respeito vem numa das cartas de Carlo, datada de junho de 1957 e dirigida à esposa. A visão feminina do caso (ou o outro lado da história) surge na resposta de Anna. Essa outra carta esclarece também certa postura do marido e o fato de sempre repetir ao filho que ela iria reencontrar-se com Carlo por causa dele, já que os adolescentes precisam do pai.

É importante relatar que essas cartas, já amareladas pelo tempo, foram encontradas por Nino, numa gaveta do quarto dos pais, quando procurava por um frasco de aspirinas para aliviar uma forte dor de cabeça.

$\mathrm{Na}$ primeira carta, Carlo conta que todas as sextas-feiras costuma ir à taverna Mozart, para se encontrar com os amigos de sua terra natal. Certo dia, encontrou-se só com um homem de Santa Croce, onde ainda moravam a esposa e um filho de doze anos. Visivelmente transtornado, depois do quinto copo de bebida, o homem lhe confiou que recebera cartas anônimas que acusavam sua mulher de adultério. Sua vergonha era tão grande que ele deixou de trabalhar e raramente saía de casa. Ficou ali chorando o resto da noite. Ao deixá-lo, Carlo suplicou-lhe que fosse à sua casa no dia seguinte, mas ele não apareceu. Uma semana depois, sua foto estava nos jornais. Abaixo da foto, um jornalista escreveu: "Un Italien repêché des eaux du Saint Laurent. La police n'exclut pas l'hypothèse d'un règlement de compte". ${ }^{16}$ Em seguida, Carlo pergunta o que se diz a respeito desse caso no vilarejo.

$\mathrm{Na}$ resposta de Anna, datada do mês seguinte, sabe-se que, por toda a região, não se falou em outra coisa senão do afogado do São Lourenço e de sua viúva. Ele havia emigrado em 1949. No princípio, escrevia uma vez por mês e enviava todas as suas economias para a mulher, assim como Carlo. Com o passar dos anos, as cartas se tornaram cada vez mais raras e o dinheiro só aparecia no Natal e na Páscoa. Ele não queria voltar nem levar a família para junto de si. Todos no vilarejo sabiam que ele tinha uma amante em Montreal, do mesmo modo que Carlo. Recentemente, estivera em Rotello, em casa de sua irmã. Voltara com a firme intenção de matar sua mulher, que o havia desonrado.

\footnotetext{
15 "Para bem te preparar para emigrar, toma nota de tudo que tu não gostas no vilarejo. Tu terás necessidade disso quando o desejo de voltar for mais forte que tudo".

16 "Um italiano repescado das águas do Saint Laurent. A polícia não exclui a hipótese de um acerto de contas".
} 
Mas antes de executar seu projeto, pediu à irmã para ver, incógnito, o filho que havia deixado com quatro anos de idade. Além de não reconhecê-lo, o menino lhe havia dito que seu pai partira para sempre e que não se incomodava em revê-lo, depois de tão longa ausência. Anna afirma, então, que nenhuma das mulheres que conhece condena aquela mulher, que havia se tornado viúva bem antes do suicídio de seu marido.

O texto relata que Nino leu e releu incansavelmente essa história, que poderia ter sido a de sua família, e, enquanto calafrios percorriam seu corpo excitado, teve de repente uma vontade louca de comer figos secos recheados de amêndoas e de fazer isso sentado entre seu avô e sua avó.

Outra marca do exílio é a dificuldade de adaptação ao novo espaço cultural. Em se tratando do Quebec, há um problema a mais: a existência de duas línguas oficiais o inglês e o francês. A esse respeito, o livro denuncia a existência de líderes, dentro da própria comunidade italiana, que, em vez de ajudar os italianos pobres, procuram manipulá-los. Acolhidos com desconfiança e até mesmo com desprezo, esses imigrantes procuraram compreensão e apoio no interior da comunidade italiana, onde encontraram valores e modos de vida mais de acordo com o que esperavam. Mas o bairro italiano, que devia ser um lugar de transição que facilitasse a sua adaptação ao novo país, tornouse o feudo de alguns políticos mal intencionados. Mercado cativo para uns, fonte exclusiva de votos para outros, eram numerosos os que queriam perpetuar a marginalização da comunidade italiana. $O$ texto aponta quatro tipos de líderes que, instigados pelo grupo anglófono, tão discreto quanto poderoso, sustentaram a defesa da escola inglesa para os falantes do italiano, mesmo sabendo que não havia melhor modo de marginalizá-los.

E quando a Lei 101 foi promulgada, os imigrantes de origem italiana se sentiram traídos, presos numa armadilha. $O$ francês era freqüentemente para eles sua terceira língua e eles ignoravam quase tudo da cultura quebequense francófona. A esse respeito, o narrador/autor revela que a maioria de seus alunos de origem italiana, grega e portuguesa acredita que a proporção dos francófonos no Quebec oscila entre quarenta e sessenta por cento, quando se sabe que essa proporção gira em torno de oitenta por cento. Além disso, eles têm preconceitos em relação aos quebequenses francófonos, entre eles o de crer que esses quebequenses não falam o real French, isto é, o verdadeiro francês. E outro fato relevante: a quase totalidade de seus alunos se opõe à independência do Quebec; a escola fez deles patriotas exaltados e ignorantes de um Canadá fictício (p. 96).

O narrador/autor ainda comenta que, antes da Lei 101, os filhos dos imigrantes, falantes de outras línguas que não o francês ou o inglês, eram marginalizados nas escolas inglesas; hoje, são marginalizados cada vez mais em francês, esquecendo que afrancesar não é sinônimo de integrar. E pergunta: "Sauront-ils malgré tout trouver la voie du métissage?"17 (p. 97).

Convém fazer aqui um parêntese para compreender melhor a questão lingüística no Quebec. No início dos anos sessenta, a legislação lingüística tornou-se, para os francófonos, um meio de ascensão social. Como o francês, no Quebec, não era a língua de uso predominante no trabalho nem nos negócios, e o inglês constituía a língua de trabalho por todo o Canadá, a escolha da escola inglesa se impunha em razão da mobilidade econômica e

17 "Saberão eles, apesar de tudo, encontrar o caminho da mestiçagem?". 
social oferecida pelo inglês. Essa situação fez com que os imigrantes, em sua maioria, tivessem a tendência de enviar seus filhos às escolas inglesas e de se assimilar à minoria anglófona. Sentindo-se prejudicados, os francófonos desejaram fazer do francês a língua de trabalho e de negócios no Quebec, com o objetivo de fazer crescer suas possibilidades sócio-econômicas e suas chances de melhoria. ${ }^{18}$

Quando a Lei 101 - promulgada em 1977 e conhecida pelo nome de "Charte de la langue française" - foi ratificada pelo governo do Partido Quebequense (o PQ), houve, em toda a província, a promoção do francês e, ao mesmo tempo, a restrição do uso do inglês. Certas instituições locais como os municípios e os conselhos escolares, que antes tinham o direito de utilizar em parte o inglês, foram forçados a utilizar exclusivamente o francês. A partir dessa época, a contratação e a melhoria no emprego iriam depender de um certo conhecimento "suficiente" do francês. ${ }^{19}$ Alain-G. Gagnon e Raffaele Iacovino explicam que "a língua francesa constitui a base para a autodefinição do Quebec como uma comunidade política. Sob esse ponto de vista, a língua é conceitualizada como um direito individual". ${ }^{20}$ Para esclarecer melhor essa idéia, Gagnon e Iacovino citam um trecho de Rocher:

No Quebec, [...] a língua francesa é apresentada como um "centro de convergência" para os diversos grupos que ainda assim podem manter e permitir que prospere sua especificidade. Enquanto a política canadense privilegia uma abordagem individualista à cultura, a quebequense defende claramente a necessidade de reconhecer o francês como um bem coletivo que requer proteção e estímulo. ${ }^{21}$

Percebe-se, portanto, que existe uma diferença fundamental entre o status do francês como língua comum na vida pública do Quebec e aquele das outras línguas. Lá, o francês é considerado uma propriedade econômica, social e cultural.

Voltando ao livro de Micone, verifica-se que a dificuldade de integração cultural ao novo país também é tratada do ponto de vista pessoal. No início, o menino freqüentou uma escola francesa e, quando começava a se familiarizar com a nova língua, dois anos depois de sua chegada a Montreal, a família se muda para perto de uma nova igreja italiana e de uma escola inglesa, que o pai o obriga a freqüentar para ficar igual a todos os outros. Nino confessa então que se sentia duplamente marginalizado: como italiano no Quebec e como aluno numa escola à margem da comunidade francófona.

Conta então um incidente acontecido em sala de aula que o marcou dolorosamente. Não tendo nenhum conhecimento do inglês, o menino se fechou num mutismo absoluto por diversas semanas. Certo dia, o professor de história fez uma pergunta sobre o fascismo. Ninguém respondeu. Nervosamente, depois de ter repetido mentalmente a resposta por duas ou três vezes, Nino emitiu sons quase ininteligíveis para grande espanto dos colegas e do professor, que andou até o outro lado da sala, olhou pela janela e, voltando-se bruscamente, apontou o dedo em sua direção, deixando escapar: "Even that guy knows!"22

\footnotetext{
${ }^{18}$ GAGNON; MONTCALM. Québec, p. 257.

${ }^{19}$ GAGNON; MONTCALM. Québec, p. 263.

${ }^{20}$ GAGNON; IACOVINO. O interculturalismo: expandindo as fronteiras da cidadania, p. 459-460.

${ }^{21}$ ROCHER; ROCHER; LABELLE. Pluriethnicité, citoyenneté et intégration. Apud GAGNON; IACOVINO. O interculturalismo: expandindo as fronteiras da cidadania, p. 221.

22 "Até esse menino sabe!".
} 
(p. 72). Nino percebeu que o professor o havia considerado um imbecil durante todo esse tempo, sem procurar saber o porquê de seu silêncio. Confessa então que nunca teve tanto ódio por um homem como naquele dia e voltou para casa no meio do recreio, determinado a nunca mais pôr os pés nessa escola. Isso, porém, não aconteceu.

Quando terminou o curso secundário na escola inglesa, Nino voltou à sua aldeia natal para visitar o avô e ficou conhecendo seu tio, um jovem professor que havia estudado no seminário de Nápoles e agora ensinava latim e francês no ensino médio. $\mathrm{O}$ jovem se encantou com a eloqüência do tio e com sua numerosa biblioteca, maior do que a biblioteca municipal. Procurando compreender de onde provinha a algaravia que o sobrinho falava, o tio soube que Nino falava o inglês com os professores, o italiano logo que saía da sala de aula, o francês com as moças do bairro e o dialeto com os pais. Soube ainda que, na escola inglesa, os autores quebequenses não faziam parte do currículo. Se não fosse o fato de alguns trechos de La petite poule d'eau servir de material para o estudo da concordância do particípio passado, os alunos não teriam sabido que, no Canadá, ao menos um livro tinha sido escrito em francês. Curiosamente, foi com o tio, na Itália, que Nino tomou um contato mais íntimo com a literatura do Quebec, em particular com a obra de Gabrielle Roy.

Mas o que mais marcou Nino, nessa viagem à terra natal, foi o reencontro com o avô e com a sua figueira. Pouco antes da sua partida para o Canadá, o menino havia plantado uma figueira para o avô. Ele havia declarado ao neto que desejava ter uma lembrança viva dele, daí a idéia da figueira.

Só depois de uma semana no vilarejo é que Nino consegue ir com o avô ao vinhedo, para ver a sua figueira. Fica embevecido ao contemplá-la. Parecia estar diante de uma árvore encantada. Em um dos galhos, o avô havia enxertado um outro tipo de figueira. Figos avermelhados estavam lado a lado com outros de cor verde, três vezes maiores. "Eu nunca teria imaginado que isso fosse possível”, exclamou entusiasmado. Depois de perscrutar o olhar do neto, o avô disse: "Cuidei dela como se fosse você". A figueira apresenta-se, portanto, como uma metáfora de Nino. Ela é híbrida, assim como a sua cultura:

Ni tout à fait italienne, ni tout à fait québécoise, ma culture est hybride. En plus de cette ville, je porte en moi le village qui jadis s'arracha à sa colline pour se tapir dans la mémoire de chaque déraciné. ${ }^{23}$ (p. 100)

De fato, nenhuma cultura pode absorver completamente uma outra nem evitar ser transformada ao seu contato. A cultura do imigrante, assim como todas as culturas, engloba domínios da experiência que não podem ser inteiramente traduzidos pela língua e ainda menos por uma só língua. A cultura do imigrante, nas palavras do texto, é um "palimpsesto impossível” (p. 99). Não há cultura italiana, grega, portuguesa ou haitiana no Quebec, mas modos de viver e pensar próprios aos quebequenses dessas mesmas origens. A cultura imigrada é uma cultura de transição que, por falta de poder sobreviver como tal, poderá, numa troca harmoniosa, fecundar a cultura quebequense e assim se perpetuar nesse espaço.

23 "Nem completamente italiana, nem completamente quebequense, minha cultura é híbrida. Além desta cidade, carrego em mim o vilarejo que antigamente se arrancou de sua colina para se esconder na memória de cada expatriado". 


\section{RÉ S U MÉ}

Il s'agit, dans cette étude, de la question de l'exile dans Le figuier enchanté, de Marco Micone, un auteur italien émigré au Québec. L'auteur révèle la problématique de l'adaptation dans un autre pays, à travers une vision personnelle et collective à la fois, en montrant que la culture de l'immigré est toujours hybride, un palimpseste impossible.

\section{O T S - C LÉ S}

Exile. Culture de l'immigrant. Littérature québécoise.

\section{REFERÊNCIAS}

CHARTIER, Daniel. Dictionnaire des écrivains émigrés au Québec: 1800-1999. Québec: Éditions Nota Bene, 2003.

DURAND, Thierry. L'écriture ou la vie. Essai sur la biographie. Études Françaises, Montréal, Les Presses de l'Université de Montréal, v. 33, n. 3, 4. trimestre 1997.

GAGNON, Alain-G.; IACOVINO, Raffaele. O interculturalismo: expandindo as fronteiras da cidadania. Trad. Mariana Lustosa. In: GAGNON, Alain-G. (Org.) Quebec: Estado e sociedade. Trad. Zilá Bernd et al. Porto Alegre: Editora UFRGS, 2003. p. 449-474. GAGNON, Alain-G.; MONTCALM, Mary Beth. Québec: au-delà de la révolution tranquille. Texte traduit de l'anglais par Pierre Desruisseaux et révisé par les auteurs. Montréal: VLB éditeur, 1992.

HAREL, Simon. Le voleur de parcours: identité et cosmopolitisme dans la littérature québécoise contemporaine. Montréal: Le Préambule, 1989.

MICONE, Marco. Le figuier enchanté. Montréal: Boréal, 1998.

WEINMANN, H.; CHAMBERLAND, R. (Dir.). Littérature québécoise: des origines à nos jours. Montréal: Hurtubise, 1996. 